\title{
Assessment of the Hip and Knee Flexion Contractures in Cerebral Palsy Patients with Crouch Gait
}

\author{
Çömelme Pozisyonunda Yürüyen Beyin Felçli Hastalarda Kalça ve Dizdeki Fleksiyon \\ Kontraktürlerinin Değerlendirilmesi
}

\author{
Fuat Bilgili', Yener Temelli², N. Ekin Akalan ${ }^{3}$ \\ 1'Department of Orthopaedics and Traumatology, Taksim Training and Research Hospital, ístanbul, Turkey \\ ${ }^{2}$ Department of Orthaopedics and Traumatology, Gait Analysis Laboratory, Faculty of Medicine, İstanbul University, İstanbul, Turkey \\ ${ }^{3}$ Division of Physiotherapy and Rehabilitation, Faculty of Health Science, İstanbul University, İstanbul, Turkey
}

\begin{abstract}
The knee is the most affected joint in children with cerebral palsy. Flexion contracture of the knee is the cause of the crouch gait pattern, instability in stance phase of gait, and difficulties during standing and sitting, and other daily living activities. Hip flexion contracture in crouch gait is mostly compensation of the knee flexion contracture and ankle equines. The psoas muscle is the primary reason for the hip flexion contracture and is known to be associated with increased anterior pelvic tilt, crouching gait, hip instability and lumbar lordosis. Children with cerebral palsy may even give up walking due to the high energy demand in the adult period. The purpose of this article is to review the causes of the knee and hip flexion contractures, clinical evaluations, and treatment principles in children with cerebral palsy. The biomechanical reasons of knee and hip flexion deformity are discussed in detail in the light of previous studies and gait analysis data. (JAREM 2012; 2: 33-7)
\end{abstract}

Key Words: Cerebral palsy, child, contracture, gait, hip joint, knee joint, muscle, skeletal, tendons

\section{ÖZET}

Beyin felcinde en çok etkilenen eklem diz eklemidir. Diz fleksiyon kontraktürü, çömelme pozisyonunda yürümeye, basma fazında stabilite kaybına, ayakta durma ve oturmada ve günlük yaşam aktivitelerinde zorluklara yol açar. Kalça fleksiyon kontraktürü yürüyüş sırasındaki çömelmedeki kalça fleksiyon kontraktürü sıklıkla diz fleksiyonu ve ayak bileği ekinusunun kompansasyonu içindir. Kalça fleksiyon kontraktürünün primer sebebi ise psoas kasıdır ve neticesinde artmış anterior pelvik tilt, çömelme yürüyüşü, kalça instabilitesi ve lomber lordozla ilişkili olduğu bilinmektedir. Bu çocuklar ileri yaşlarda, yüksek enerji gerektirdiği için yürümeden bile vazgeçebilirler. Bu yazıda, beyin felçli çocuklarda diz fleksiyon kontraktürlerinin nedenleri, klinik değerlendirmeler ve tedavi prensipleri gözden geçirildi. Ayrıca, yapılan çalışmalar ve yürüme analizi verileri ışığında diz fleksiyon kontraktürünün biyomekaniksel nedenleri ayrıntılı olarak tartışıldı.(JAREM 2012; 2: 33-7)

Anahtar Sözcükler: Beyin felci, çocuk, kontraktür, yürüyüş, kalça eklemi, diz eklemi, kas, iskelet, tendon

\section{INTRODUCTION}

In the literature, crouch gait is reported in $69 \%$ of the general CP population, being $74 \%$ in diparetic and $88 \%$ in quadriparetic patients (1).

Delay in walking and hip flexion cause high femoral anteversion in children with CP. With increased anteversion, the child walks with internal rotation and pelvic tilt increases. Increased femoral anteversion is associated with kinetic and kinematic changes that result in crouch posture. Normally, ground reaction force (GRF) passes from the center of the hip and knee while standing. In children with crouch gait, the GRF passes from the anterior of the hip and posterior of the knee because of hip flexor tightness. Lumbar lordosis is increased. To compensate for lumbar lordosis, the superior part of the trunk moves back and the knee is flexed. This crouching posture at the hip and knee leads to knee flexion contracture over time (2). Therefore, prior to initiating treatment for the crouch gait in children with $\mathrm{CP}$, the appropriate therapeutic strategy should be determined through a qualified assessment of the flexion contracture in the hip and knee.
The aim of this review article is to investigate the reasons of hip and knee flexion contracture in children with $\mathrm{CP}$, analyze the compensatory alterations that may be associated with deformities and to determine most appropriate treatment method for these patient.

\section{KNEE FLEXION CONTRACTURE}

Hamstring spasticity is the most common problem in cerebral palsy (CP). If left untreated, it results in knee flexion contractures (3). The quadriceps muscle works excessively as a result of knee flexion contracture. This increases the load on several joints, especially on the patellofemoral joint and becomes an important problem, causing anterior knee pain and stress fractures of the patella and tibial tubercle $(2,4,5)$. Knee flexion contracture may develop (i) after hip flexion contracture and increased anterior pelvic tilt, or due to (ii) hamstring spasticity or contracture, (iii) gastrocnemius tightness, (iv) triceps surae weakness following surgery, or ( $v$ ) posterior capsule contracture that develops over time (6-10).

Received Date / Geliş Tarihi: 10.04.2012 Accepted Date / Kabul Tarihi: 21.06.2012 C) Telif Hakkı 2012 AVES Yayıncılık Ltd. Şti. Makale metnine www.jarem.org web sayfasından ulaşılabilir. C) Copyright 2012 by AVES Yayinclik Ltd. Available on-line at www.jarem.org doi: 10.5152/jarem.2012.11 


\section{i) Hamstring spasticity or contractures}

Medial and lateral hamstrings attached to the proximal tibi are knee flexors and hip extensors (11). Three-dimensional gait analysis studies showed prolonged medial hamstring muscle activity resulting in increased hip extensor muscle strength (9). It has long been believed that children with crouch gait have hamstring spasticity and this has been the focus of several studies. Many have shown that hamstring lengths are usually normal in these children $(2,6,9,12)$. Even though the length of the hamstring is normal, it appears contracted when pelvic tilt increases. Hamstring release in this condition will further increase the pelvic tilt. Thus, the hamstring release operation should be decided after clinical tests and three-dimensional gait analysis which provides dynamic length measurement of hamstring muscles $(2,9,12,13)$.

\section{ii) Knee flexion contracture following hip flexion contracture and increased anterior pelvic tilt}

Anterior pelvic tilt and knee flexion are usually increased in children with CP while standing or during the stance phase of gait $(2,7,9,13)$. Normally, ground reaction force (GRF) passes from the center of the hip and knee while standing. In children with crouch gait, the GRF passes from the anterior of the hip and posterior of the knee because of hip flexor tightness. Lumbar lordosis is increased. To compensate for the lumbar lordosis, the superior part of the trunk moves back and the knee is flexed (2). This crouching posture at the hip and knee leads to knee flexion contracture over time. Increased knee flexion associated with increased anterior pelvic tilt contributes to knee flexion contracture in time. As anterior pelvic tilt continues to increase, knee flexion during standing and walking will increase. Usually this might be perceived as an increase in knee flexor tightness clinically, necessitating hamstring lengthening.

\section{iii) Gastrocnemius tension}

The gastrocnemius muscle is the primary ankle plantar flexor and knee flexor (10). As knee flexion increases, flexion moment of the gastrocnemius at the knee gradually increases. There is selective motor deficit in the gastrocnemius muscle of children with $\mathrm{CP}$ and spasticity dominates. For this reason, it is usually stretched, causing early heel rise, toe walking, and heel valgus during the stance phase of gait (2). Gastrocnemius causes toe walking distally and this forms an extra proximal moment pulling the knee to flexion (10). This moment directly affects acceleration of the knee to flexion at the end of the stance phase and contributes to maximum flexion of the knee during the swing phase (14). Gastrocnemius-soleus complex is the most important part of plantar flexion-knee extension couple which provides adequate knee extension during the stance phase (2). While gastrocnemius muscle stretch occurring in the proximal contributes to increased knee flexion, it loses its important role in extension during the stance phase and becomes a knee flexor (15).

\section{iv) Postoperative triceps surae weakness}

Soleus generates $40 \%$ to $50 \%$ of the total force needed to straighten the body during the first one-third of the gait cycle (2). This activity enables knee flexion by producing a moment against the GRF passing from the anterior of the ankle. This plantar flexor effect on the ankle and extensor effect on the knee is called plantar flexion-knee extension couple. Thus, extra muscle activation for knee extension during the stance phase is eliminated. In spas- tic diplegia and quadriplegia, the gastrocnemius and hip flexor muscles stretch while the soleus, vastus muscles, and gluteus maximus elongate. Any procedure that weakens the soleus such as selective dorsal rhizotomy or Achilles tendon release results in deficiency of the soleus to retract the tibia. As a result, ankle dorsiflexion and knee flexion increase during the stance phase, leading to the crouch gait pattern and knee flexion contracture (2).

\section{v) Posterior knee capsule tightness}

Knee flexion contracture leads to shortening and thickening of the posterior capsule and shortening of the sciatic nerve (16). For this reason, particularly in fixed knee contractures of $30^{\circ}$ to $40^{\circ}$, it is suggested that hamstring release be combined with posterior capsule release $(2,16)$.

\section{Assessment methods of knee flexion contracture}

Knee flexion contractures are assessed clinically and by laboratory and imaging studies.

\section{i) Clinical assessment methods}

Patients on their mothers' lap or walking with the help of an assistive device (walker, canadian crutch, cane) should be observed for lower extremity position and activity. Posterior pelvic tilt, lumbar kyphosis and forward bending of the trunk while sitting give clues about possible hamstring contracture and/or trunk hypotonicity. In order to determine the underlying cause of knee flexion contracture, hamstring muscles should first be assessed. The popliteal angle never exceeds $50^{\circ}$ throughout life. However, it may increase up to $90^{\circ}$ in CP. Thus, in the first instance, the popliteal angle and hamstring contracture should be assessed. During this test, the physician observes whether hamstring spasticity and dynamic contracture are present by increasing the speed of passive knee extension (9). Measurement of the hamstring length is important to distinguish between normal and contracted muscle lengths. The popliteal angle is measured both unilaterally and bilaterally. Hamstring shift is calculated by subtracting unilateral popliteal angle from bilateral popliteal angle. Unilateral popliteal angle is measured while the patient's existing lumbar lordosis is preserved and the contralateral hip is in neutral position. It gives information on functional hamstring contracture. However, bilateral popliteal angle is measured by bringing the contralateral hip to flexion until the ASIS (anterior superior iliac spine) and PSIS (posterior superior iliac spine) are vertical. Then, the ipsilateral popliteal angle is measured, which provides information about true hamstring contracture. The difference between the two angles shows whether the hamstring length is normal or not. If the difference is greater than normal, this means that hamstring tightness decreases with posterior rotation of the pelvis, suggesting normal hamstring length. In general, anterior pelvic tilt is increased in patients with spastic diparesia and quadriparesia, with a greater hamstring shift. If the clinician determines functional hamstring contracture without bringing pelvic tilt to normal and performs hamstring release, this will further decrease hip extensor moment of hamstrings, increase pelvic tilt, and as a result of contracted hip flexors, end up with knee flexion during gait $(10,13,17)$. Delp et al. (13) found that every $1^{\circ}$ increase in pelvic anterior tilt increased the bilateral popliteal angle by $2^{\circ}$. Thus, a difference of greater than $20^{\circ}$ between unilateral and bilateral popliteal angles often suggests hip flexor contracture, weak abdominal muscles and/or weak hip extensor muscles. Consider- 
ing the difficulties in clinical measurement of dynamic hamstring length, evaluation of the patient in gait analysis laboratory is necessary (10). Clinically, gastrocnemius-soleus tightness should be assessed separately as with the hamstring muscles, because the soleus muscle is usually normal or extended in most CP patients (7). The primary role of the soleus is to control the forward movement of the tibia during the mid-stance phase, thereby enabling knee extension. Radical soleus stretching exercises and surgical procedures such as Achilles tendon release that cause excessive lengthening of the soleus weakens the muscle, resulting in increased knee flexion during the stance phase and knee flexion contracture. The Silfverskiold test performed under anesthesia is the most appropriate method to identify gastrocnemius contracture and excessive soleus length. However, the positioning of the mid and front segments of the feet should not interfere with the test. Thus, the subtalar joint is brought to as neutral or varus position as possible during the test (10).

For children with femoral anteversion and tibial external torsion, application for one year of elastic derator-band in physiotherapy causes increase in walking distance and walking velocity with reduction in energy expenditure. However, the long-term use is still controversial (18). If orthopedic procedures are considered, correction of rotational deformities is the first line of treatment for crouch posture in CP patients (2). Clinically, video-based observational gait analysis (VBOGA) may help understand the influence of knee flexion contracture on walking. The clinical application of this method can be made by a single specialist experienced in VBOGA. It has been shown that observation of the gait in slow motion and evaluation of the gait in fewer phases (dividing the stance phase to three parts only) with a simple evaluation form increase reliability $(19,20)$. Even though detailed and time consuming, Perry's observational gait analysis evaluation form developed in 1992 is still used for gait assessment $(4,20)$.

\section{ii) Computerized gait analysis}

In CP patients with knee contracture, kinetic analysis of gait shows increased knee flexion in the stance phase and, despite minimal movement of the knee in the swing phase, an increase in the knee extensor moment during the loading phase, and increased quadriceps activity, depending on the severity of contracture. This is because the extensor muscles are trying to bring the knee to extension (2). Knee flexion contracture is not examined in the laboratory solely in the knee context, and investigation of its effects on other joints is helpful for the treatment. In spastic diplegia and quadriplegia, usually crouch gait is seen. Foot dorsiflexion and knee flexion are increased due to soleus weakness and/ or femoral anteversion and knee extensor moment continuously increase. EMG shows increased hip and knee extensor muscle activity and high energy consumption (2). With the addition of ankle plantar flexion during the stance phase to this picture, the knee is flexed at the beginning of the stance phase.

\section{Management of knee flexion deformities}

The goals of treatment should be as follows:

1. Decrease knee flexion during gait,

2. Increase stride length,

3. Decrease patellofemoral joint load, and

4. Increase strength (durability).
In principle, the pelvis, hip, knee, and ankle should be assessed as a whole.

1. Rotational deformities (femoral anteversion, tibial torsion, varus-valgus-adductus deformities of the feet, hip subluxation, etc.) should be corrected.

2. Shortened muscles should be lengthened (care should be given to biarticular muscles).

3. Elongated muscles should be shortened.

4. Fixed joint contractures should be corrected.

5. Ground reaction orthosis may be needed.

In mild knee flexion contractures, immobilizer, angle adjustable $\mathrm{KAFO}$, and botulinum toxin A injection can be used in children younger than 5 years age whose popliteal angle is smaller than 60 degrees. Botulinum toxin A injection should be used in carefully selected patients. Corry et al.(21) showed that anterior pelvic tilt increased after botulinum toxin $A$ injection to hamstring muscles in $10 \mathrm{CP}$ patients with crouch gait. Care should be taken not to cause isolated hamstring weakness. As the hamstring is a hip extensor, its excessive weakness increases anterior pelvic tilt.

If knee flexion contracture is between 10 to 30 degrees, surgery is necessary in patients older than 10 years. Hamstring lengthening and, if necessary, posterior knee capsulotomy operations can be performed. Gradual correction with casting may be rarely necessary. No deformity has developed in femoral condyles (3).

\section{Indications of hamstring lengthening}

1. Popliteal angle is greater than $50^{\circ}$ under anesthesia and knee flexion is greater than $20^{\circ}$ while standing,

2. Fixed knee contracture is greater than $5^{\circ}-10^{\circ}$,

3. Having difficulty sitting and standing without a wheelchair,

4. Disappearance of lumbar kyphosis while sitting with hamstring relaxation.

Semitendinosus, semimembranosus, and long head of the biceps femoris are knee flexors and hip extensors. Semitendinosus and semimembranosus lengthening may correct the popliteal angle separately by 10 to 15 degrees. Excessive hamstring lengthening should be avoided because it causes anterior pelvic tilt and stiff knee gait. If the biceps femoris is not lengthened intramuscularly, it may lead to tibial external rotation.

Should we use passive hamstring stretching?

Instead of long-term aggressive hamstring stretch exercises, functional stretching and relaxation methods can be more effective in relaxing the child's tight muscles and whole body during play (22).

If fixed knee flexion contracture is greater than $30^{\circ}$, the distal ends of the femoral condyles may become flattened, disrupting the articular surface of the tibiofemoral joint. In this situation, distal femoral extension osteotomy is a better option than capsular release (3). Capsular release in the presence of flattened femoral condyles results in decreased slide/roll behavior of the tibiofemoral joint, turning the knee joint into a hinge joint rather than a sliding one around the condyles. Hamstring lengthening, patellar tendon plication, and distal tibial tubercle transfer may be performed in the same session after supracondylar osteotomy. Since distal 
femoral extension will cause femoral shortening, the development of sciatic nerve palsy will be much rarer. Supracondylar closing wedge extension osteotomy of the femur is an effective and safe procedure for the correction of knee flexion contracture in adult patients with spastic diparesis. One advantage of this operation is femoral shortening and relief of neurovascular structures. Sciatic nerve neuropathy and vascular insufficiency are rare (9).

Temporary growth arrest of anterior femoral epiphysis is a new method used in the management of knee flexion contractures (9). This method should be used in patients around 13 years of age, with 5 to 20 degrees of flexion contracture. Genu recurvatum deformity develops in patients under 13 years of age and deformity correction is incomplete in patients older than 14 years.

\section{Results and problems}

Potential problems related to treatment include:

1. Recurrence of knee flexion deformity.

2. Increases in postoperative lumbar lordosis and anterior pelvic tilt should be avoided. If present, hip flexion contracture should also be corrected.

3. In the presence of quadriceps spasticity or if the hamstrings are too weak, stiff knee gait or

genu recurvatum will ensue. Distal rectus femoris transfer will solve the problem.

4. Partial correction of knee flexion deformity.

5. Crouch gait may develop due to excessive triceps lengthening. The solution is ground reaction AFO usage.

6. Sciatic nerve lesion.

As a principle, the pelvis, hip, knee, and ankle should be assessed as a whole. Rotational deformities should be corrected initially. Muscle length should be balanced, fixed joint contractures should be corrected, and recurrence of fixed contractures should be avoided by using ground reaction orthoses.

\section{HIP FLEXION CONTRACTURE}

While the hip flexion contractures are more common in patients with diplegia and quadriplegia, they are relatively rare in hemiplegic patients. Crouch gait is mostly for the compensation of the knee flexion and ankle equinus (23).

Psoas muscle is the primary reason for the hip flexion contracture and is known to be associated with increased anterior pelvic tilt, crouch gait, hip instability and increased lumbar lordosis. In patients with cerebral palsy, the psoas is shorter and the maximum hip extension is lower compared to the control group (24).

To assess the presence of the contracture, a clinical examination using the Thomas and Staheli tests is required. Thomas test is performed, keeping the patient in the supine position; to correct the lumbar lordosis and fix the pelvis, and the other hip and knee are put in full flexion. The angle between the femur of the tested side and the examination table indicates the grade of the hip flexion contracture. In the Staheli test, the patient lies in the prone position and the hip is left outside the examination table. The hip of the examined side is put in passive extension until pelvis extension is observed (23).

The spasticity of the iliopspas muscle causes an increase in the hip flexion in the stance phase. In the mid-stance phase, the hip turns into normal extension and at the end of the stance phase, the hip rapidly shifts to flexion to lift the lower extremity from the floor and enter the swing phase. In patients with a crouch gait, the hip is in preflexion at the end of the stance phase and the power generation from the iliopsoas is lost. In addition, the step length reduces as the contracture gets worse. In patients with hip flexion contracture, anterior pelvic tilt and increased lumbar lordosis are observed during walking. If the increased flexion observed in the hip does not result from the contracture but instead from the hamstring and gastrocnemius spasticity, the hip extension will improve following the lengthening of the hamstring and gastrocnemius. If contracture exists despite this, anterior pelvic tilt will persist following hip and knee surgery and the patient will bend forward during walking. Lengthening of the iliopsoas should be added to the surgical intervention to be performed in such a case. Release of the iliopsoas from the small trochanter causes unnecessary weakening of the hip flexors and worsens walking. It becomes difficult to climb stairs. The strength of the muscle is better preserved by psoas tenotomy performed at the pelvic brim $(23,25)$. The psoas tendon is identified and selectively sectioned from the iliacus muscle and the psoas is retracted into the intact iliacus muscle (26). No post-surgical immobilization is required; however the patients are not allowed to sit in the wheelchair where the hips would remain in flexion, to protect the hip extension (23).

On the other hand, proximal femoral derotation ostetomy may improve the dynamic psoas length, even though no psoas procedures is performed, by moving the lesser trochanter forward (24).

The same activity as the gastrocnemius-soleus activity observed during the plantar flexion knee extension couple also exists between the iliacus and the psoas. The same weakness as the soleus weakness that causes an increase in the forward progression of the tibia and thus crouch gait, is also observed in cases of iliopoas tenotomy with a weakening the iliacus. As we know, the muscles covering double joints are affected more in cerebral paresis. The iliacus, just like the soleus, spans a single joint and is not affected by spasticity similar to its partners (gastrocnemius and psoas). While the iliacus muscle is involved in carrying forward the femur same as the psoas, it gets very weak after the tenotomy and reduces the hip flexor force at the end of the stance phase and at the beginning of the swing phase (27). Children with cerebral palsy very commonly develop a stiff knee gait pattern and most of them are being treated by distal rectus femoris transfer surgery. One of the reasons for the over-activity of rectus femoris is the posterior pelvic tilt associated with iliacus weakness and the effort by the rectus femoris to balance the pelvic tilt on the sagital plane (28). We know that one of the causes of stiff knee walking is the hip flexor weakness. Just as in the achilles tenotomy on the ankle, the tenotomy of the iliopsoas common tendon at the hip needs to be paid attention to.

Conflict of interest: No conflict of interest was declared by the authors.

\section{REFERENCES}

1. Wren TA, Rethlefsen S, Kay RM. Prevalence of specific gait abnormalities in children with cerebral palsy: influence of cerebral palsy subtype, age, and previous surgery. J Pediatr Orthop 2005; 25: 79-83.[CrossRef] 
2. Gage JR. Treatment principles for crouch gait. In: Gage JR, editor. The treatment of gait problems in cerebral palsy. London: Mac Keith Press; 2004. p. 382-97.

3. Freeman M. Gait. In: Cerebral palsy. New York: Springer; 2005. p. 251-386.

4. Sutherland DH, Davids JR. Common gait abnormalities of the knee in cerebral palsy. Clin Orthop Relat Res 1993; 288: 139-47.

5. Topoleski TA, Kurtz CA, Grogan DP. Radiographic abnormalities and clinical symptoms associated with patella alta in ambulatory children with cerebral palsy. J Pediatr Orthop 2000; 20: 636-9.[CrossRef]

6. Arnold AS, Anderson FC, Pandy MG, Delp SL. Muscular contributions to hip and knee extension during the single limb stance phase of normal gait: a framework for investigating the causes of crouch gait. J Biomech 2005; 38: 2181-9.[CrossRef]

7. Ounpuu S, Gage JR, Davis RB. Three-dimensional lower extremity joint kinetics in normal pediatric gait. J Pediatr Orthop 1991; 11: 341 9.[CrossRef]

8. Kirtley C. Support and forward progression. In: Clinical gait analysis: theory and practice. London: Churchill Livingstone; 2006. p. 237-54. [CrossRef]

9. Horstmann HM, Bleck EE. Knee. In: Orthopaedic management in serebral palsy. 2nd ed. London: Mac Keith Press; 2007. p. 303-43

10. Trost J. Physical assessment and observational gait analysis. In: Gage $J R$, editor. The treatment of gait problems in cerebral palsy. London: Mac Keith Press; 2004. p. 71-89.

11. Waters RL, Perry J, McDaniels JM, House K. The relative strength of the hamstrings during hip extension. J Bone Joint Surg Am 1974; 56: 1592-7.

12. Arnold AS, Liu MQ, Schwartz MH, Ounpuu S, Delp SL. The role of estimating muscle-tendon lengths and velocities of the hamstrings in the evaluation and treatment of crouch gait. Gait Posture 2006; 23: 273-81.[CrossRef]

13. Delp SL, Arnold AS, Speers RA, Moore CA. Hamstrings and psoas lengths during normal and crouch gait: implications for muscletendon surgery. J Orthop Res 1996; 14: 144-51.[CrossRef]

14. Goldberg SR, Anderson FC, Pandy MG, Delp SL. Muscles that influence knee flexion velocity in double support: implications for stiff-knee gait. J Biomech 2004; 37: 1189-96.[CrossRef]

15. Seth A, Liu MQ, Schwartz MH, Anderson FC, Delp SL. Treatment insight from subject-based simulation of crouch gait. In: North American Congress on Biomechanics (NACOB.; August 5-9, 2008; Ann Arbor, Michigan, USA. No: 543.
16. Acevedo JS. The infant and child with cerebral palsy. In: Tecklin JS, editor. Pediatric physical therapy. 4th ed. Philadelphia: Lippincott Williams \& Wilkins; 2007. p. 179-253.

17. Schutte LM, Hayden SW, Gage JR. Lengths of hamstrings and psoas muscles during crouch gait: effects of femoral anteversion. J Orthop Res 1997; 15: 615-21.[CrossRef]

18. Marcucci A, Eduard P, Loustalet E, d' Anjou MC, Gautheron V, Degache F. Efficieny of flexible derotator in walking cerebral palsy children Annals of Physcal and Rehabilitation Medicine 2011; 54: 337-47.

19. Akalan NE. Serebral parezili cocuklarda video bazlı gözlemsel yurume analizinin gozlemci ici ve gozlemciler arası guvenilirliğinin belirlenmesi [Yuksek lisans Tezi]. İstanbul: İstanbul Universitesi Sağlık Bilimleri Enstitusu; 1999.

20. Krebs DE, Edelstein JE, Fishman S. Reliability of observational kinematic gait analysis. Phys Ther 1985; 65: 1027-33.

21. Corry IS, Cosgrove AP, Duffy CM, Taylor TC, Graham HK. Botulinum toxin A in hamstring spasticity. Gait Posture 1999; 10: 206-10. [CrossRef]

22. Halbertsma JP, Göeken LN. Stretching exercises: effect on passive extensibility and stiffness in short hamstrings of healthy subjects. Arch Phys Med Rehabil 1994; 75: 976-81.

23. Karol LA. Surgical management of the lower extremity in ambulatory children with cerebral palsy. J Am Acad Orthop Surg 2004; 12: 196-203.

24. Choi SJ, Chung CY, Lee KM, Kwon DG, Lee SH, Park MS. Validity of gait parameters for hip flexor contracture in patients with cerebral palsy. J Neuroeng Rehabil 2011; 8: 4.[CrossRef]

25. Sutherland DH, Zilberfarb JL, Kaufman KR, Wyatt MP, Chambers HG. Psoas release at the pelvic brim in ambulatory patients with cerebral palsy: Operative technique and functional outcome. J Pediatr Orthop 1997; 17: 563-70.[CrossRef]

26. Skaggs DL, Kaminsky CK, Eskander- Rickards E, Reynolds RA, Tolo VT, Bassett GS. Psoas over the brim lengthenings: Anatomic investigation and surgical technique. Clin Orthop 1997; 339: 174-9. [CrossRef]

27. Stout LJ, Novacheck T, Gage JR, Schwartz MH. Treatment of crouch gait. In: James R. Gage, Michael H. Schwartz, Steven E. Koop, Tom F. Novacheck,"The Identification and Treatment of Gait Problems in Cerebral Palsy" Mc. Keith Press London, 2009; 555-79.

28. Fox MD, Delp SL. Contributions of muscles and passive dynamics to swing initiation over a range of walking speeds, J Biomech 2010; 43 : 1450-5. [CrossRef] 